\title{
The Weight of Schoolbags and Musculoskeletal Pain in Children of Selected Schools in Thimphu, Bhutan: A Cross- sectional Study.
}

\author{
Thinley Dorji, 1,2 Saran Tenzin Tamang, 3 Sonam Yoezer, 3 Kuenzang Wangdi.4
}

\begin{abstract}
Background: The carriage of loads on the back in children, $>10 \%$ of one's body weight (BW), induces postural change and morbidity related to spinal pain. We studied the weight of schoolbags and the prevalence of musculoskeletal pain related to carrying schoolbags among children in Thimphu, Bhutan. Methods: This was a cross-sectional study, with a multistage cluster sampling, conducted amongst grade 8 and 10 students. Data were collected using a standardized self-administered questionnaire and weights of students and schoolbags were measured. Descriptive statistics were used to present the findings. Means were compared using t-test and risk factors were identified using logistic regression. Results: There were 131 students whose schoolbags weighed $>10 \%$ body weight (BW). The mean weight of schoolbags was $4.6 \pm 1.5 \mathrm{~kg}$ for grade 8 students and $4.0 \pm 1.5 \mathrm{~kg}$ for grade 10 students. Musculoskeletal pain in at least one body region was reported by 411 students. Schoolbags weighing $>10 \%$ BW and carrying the bags over only one shoulder were significant risk factors for reporting musculoskeletal pain. There were 197 students whose schoolbags did not have any safety feature; students did not use them consistently even if they were present. Conclusions: The weight of school bags that were more than the recommended, $10 \%$ BW was a strong factor in reporting musculoskeletal pain. Parents and students may be educated on the use of schoolbags with safety features. Measures such as providing storage facilities in schools may reduce the weight of bags.
\end{abstract}

Keywords: Ergonomics; Musculoskeletal Pain; Teens; Weight-Bearing; Adolescents (Source: MeSH-NLM).

\section{Introduction}

The carriage of loads on the back on a daily basis puts considerable strain on the bodies of children causing spinal pain in the cervical, thoracic and lumbar regions.' Backpacks cause changes in the spinal posture in children with reported reduction of the lumbar lordosis, especially if the weight carried exceeds $10 \%$ of one's body weight. ${ }^{2-5}$ There is a dose-response relationship between the spinal postural changes and weight of posterior loads in school children ${ }^{2,6}$ and negative impact on the forward lean, pain and skin pressure on children's bodies.7 Estimates of the global point prevalence of spinal pain in 12-18 year old school students varies between $15-70 \% 1,8$ In Bhutan, $14.3 \%$ of the population in the age group $15-49$ years old presented to hospitals with "musculoskeletal disorders" in 2017, but the exact burden of spinal pain is unknown.?

While there is an upward trend of the prevalence of low back pain among the paediatric population, concerns have been raised about the diverse effect of musculoskeletal pain in children and their compounded effects in adulthood.8,10 The prevalence of musculoskeletal pain is reported higher in those who carry heavy schoolbags. ${ }^{8,11-14}$ Carriage of schoolbags with safety features are an important area of intervention. ${ }^{15}$ However in Bhutan, there are no standard schoolbags for students. The distances travelled by students carrying schoolbags can vary from few minutes to up to two hours, often requiring walking up mountains or slopes. ${ }^{16}$ Students carry many items other than just books and lunch boxes that add to the weight of the schoolbag.?
In recent times the weight of school bags has become a topic of concern for educators and parents in Bhutan. ${ }^{17}$ This study was conducted to determine the average weight of schoolbags in proportion to children's body weights, and the prevalence of musculoskeletal pain among schoolchildren in Thimphu, Bhutan.

\section{Methods}

\section{Design and setting}

This cross-sectional study was conducted among students studying in grades 8 and 10 under Thimphu, the capital city and the largest district by population in Bhutan. Bhutan is a small Himalayan kingdom in Southeast Asia with a population of 0.7 million. In 2017, there were 5,074 students in grades 8 and 10 in Thimphu. ${ }^{16}$ The sample size was calculated for proportions. The expected prevalence of musculoskeletal pain, given a lack of baseline data, was set at 0.5 , the margin of error 0.05 , a confidence level $95 \%$, and a design effect of 1 to give a final sample size of 441 with a $15 \%$ drop out rate.

\section{Study sample}

Multistage sampling technique was used. Six schools (three with grade 8 and three with grade 10) were randomly selected using lottery method from the list of schools in Thimphu district. ${ }^{16}$ From each selected school, sections were randomly selected using a lottery method to recruit a cluster of approximately $70 \pm 5$ students. Subjects who were diagnosed by a medical doctor as having spinal and musculoskeletal problems and those with physical handicaps were excluded.

1 MBBS. Jigme Dorji Wangchuck National Referral Hospital, Thimphu, Bhutan

${ }_{2}$ MBBS. Kidu Mobile Medical Unit, His Majesty's People's Project, Thimphu, Bhutan

3 MBBS. Faculty of Medicine, University of Peradeniya, Kandy, Sri Lanka

4 MBBS, MD. Jigme Dorji Wangchuck National Referral Hospital, Thimphu, Bhutan

About the Author: Saran Tenzin Tamang and Sonam Yoezer were medical students of Faculty of Medicine, University of Peradeniya, Sri Lanka at the time of this study. They are recipients of Royal Government of Bhutan scholarship for their undergraduate medical education. 


\section{Study questionnaire}

Data were collected using a study questionnaire that was developed for this study. The study tool partly consisted of a self-administered questionnaire in English that was pre-tested in a set of twenty students in grade 8 and twenty in grade 10 at a school. Following this, the language was simplified in several questions and two diagrams were introduced to indicate the body parts to report pain and the type of schoolbag used (backpack or satchel). The questionnaire in English was adequate and did not require translation to Dzongkha, the national language. Part A of the tool collected basic information such as age and level of physical activity. Part B collected information on musculoskeletal pain with questions derived from the Standardized Nordic Body Map Questionnaire, a validated tool used to study self-declared musculoskeletal symptoms.18 Part C collected information on the type of school bag and their safety features. In Part D, the investigators measured the height and weight of students, the weight of school bag using standard techniques and tools calibrated by the Bhutan Standards Bureau and assessed the schoolbags for the four safety features (padded shoulder strap, chest strap, hip strap and compartments).

\section{Data analysis}

The data were cleaned, entered and analysed in IBM SPSS 23.0 (trial version). The weight of schoolbag relative to student's body weight were classified into those with $\leq 10 \%$ BW and $>10 \%$ BW. Data were analysed using descriptive statistics to determine the presence/absence of musculoskeletal pain. The difference in the mean weight of school bags among students in the two grades was assessed using t-test. Adjusted analysis was performed using logistic regression to identify the risk factors for pain in the 9 body regions (neck, upper back, low back, shoulders, elbows, hands/wrists, hips/thighs, knees and ankles) in the 12-month period prior to data collection. The following factors were included in blocks to calculate adjusted odds ratio: age, sex, time spent on activities after school (screen time, playing sports), usage of safety features (padded shoulder strap, chest strap, compartments), mode of carrying (over one shoulder or both shoulders) and bag weight relative to student's body weight ( $\leq 10 \% \mathrm{BW}$ and $>10 \% \mathrm{BW})$.

\section{Ethics clearance}

Ethics clearance was obtained from the Research Ethics Board of Health, Ministry of Health, Bhutan (REBH/PO/2017/043 dated 26 April, 2017). Administrative approval was obtained from the Ministry of Education, Bhutan and respective school principals to conduct the study. Informed assent was taken from each student and consent was taken from their parent/guardian.

\section{Results}

\section{Characteristics of participants}

A total of 441 students studying in grades $8(n=190)$ and $10(n=251)$ participated in the study. There were 232 females (Table 1 ). The mean age of students studying in grade 8 was $13.6( \pm 1.3)$ years and those in grade 10 was $15.8( \pm 1.1)$ years. Half of the participants $(216,49.0 \%)$ walked to school while the rest used public $(146,33.1 \%)$ and private transport $(79,17.9 \%)$.

Table 1. The proportion of the weight of schoolbag relative to body weight among students of Thimphu, Bhutan in 2017.

\begin{tabular}{|c|c|c|c|c|c|c|c|c|}
\hline \multirow{3}{*}{\multicolumn{2}{|c|}{$\begin{array}{l}\text { Grade and } \\
\text { gender }\end{array}$}} & \multicolumn{6}{|c|}{ Bag Weight to BW (\%) } & \multirow{3}{*}{ Total } \\
\hline & & \multicolumn{2}{|c|}{$10 \%$} & \multicolumn{2}{|c|}{$>10$ to $<15 \%$} & \multicolumn{2}{|c|}{$15 \%$} & \\
\hline & & $n$ & (\%) & $n$ & $(\%)$ & $n$ & (\%) & \\
\hline \multirow{2}{*}{$\begin{array}{c}\text { Grade } \\
8\end{array}$} & Male & 57 & $(61.3)$ & 26 & (28.0) & 10 & $(10.7)$ & 93 \\
\hline & Female & 52 & (53.6) & 33 & (34.0) & 12 & (12.4) & 97 \\
\hline \multirow{2}{*}{$\begin{array}{c}\text { Grade } \\
10\end{array}$} & Male & 95 & (81.9) & 20 & (17.4) & 1 & $(0.9)$ & 116 \\
\hline & Female & 106 & $(78.5)$ & 25 & $(18.5)$ & 4 & (3.0) & 135 \\
\hline
\end{tabular}

$\mathrm{BW}=$ body weight

\section{Schoolbag weight and safety features}

The mean weight of schoolbags was $4.6 \pm 1.5 \mathrm{~kg}$ (range: $0.9-8.1 \mathrm{~kg}$ ) among grade 8 and $4.0 \pm 1.5 \mathrm{~kg}$ (range: $0.6-8.2 \mathrm{~kg}$ ) among grade 10 students. This difference in means of schoolbag weights between the two grades was $0.7 \mathrm{~kg}, p<0.001$. The mean weight of textbooks carried to school on the day of the survey was $1.9( \pm 0.7) \mathrm{kg}$ among grade 8 and $1.6( \pm 0.5) \mathrm{kg}$ among grade 10 students. Textbooks constituted nearly half of the total weight of the bag $(40.4 \%$ for grade 8 and $40.1 \%$ for grade 10 ). The percentage of students that carried bags heavier than $10 \%$ BW is shown in Table 1. A negative Pearson's correlation $r=-0.237, p<0.001$ was noted between perception on the schoolbag weight and actual weight of the schoolbag relative to BW (Figure 1).

Figure 1. The comparison between the perceived bodyweight and actual heavy schoolbag measured as $>10 \%$ body weight among students of Thimphu, Bhutan in 2017.

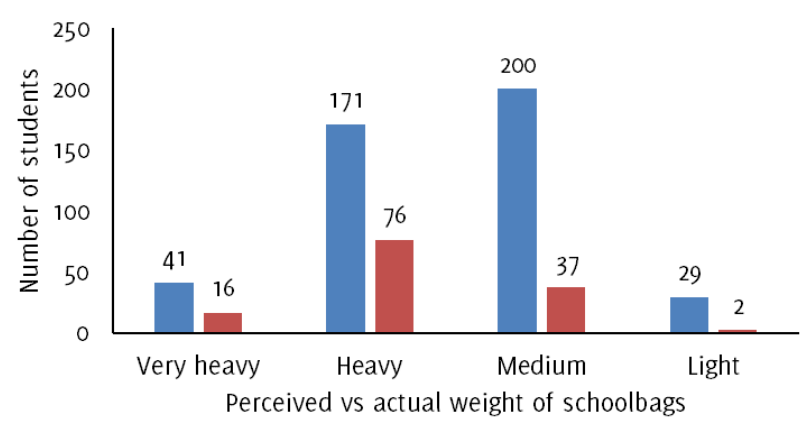

- Perceived weight Measured weight $>10 \%$ body weight

The majority of the students $(439,99.6 \%$ ) carried backpacks while two carried satchels. The backpacks were assessed for the presence of four safety features. The frequency of use of these safety features are shown in Figure 2.

Figure 2. The frequency of use of backpack safety features by students of Thimphu, Bhutan in 2017.

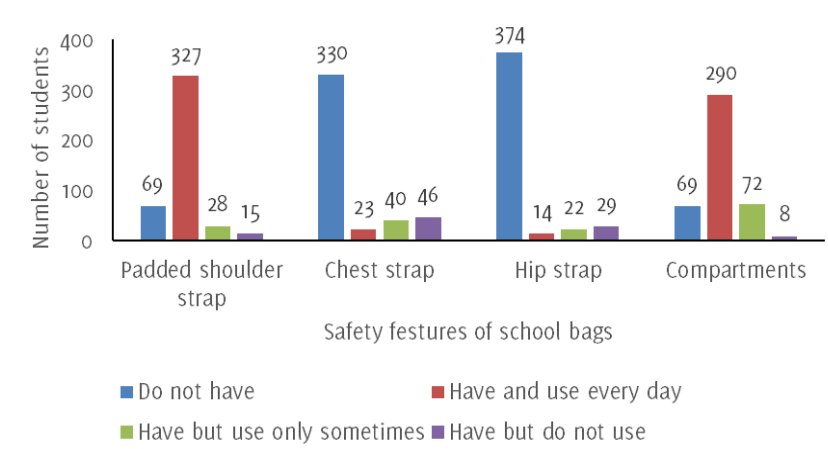

\section{Musculoskeletal pain}

The majority of the participants $(411,93.2 \%)$ reported having musculoskeletal pain in at least one of nine regions of the body during the preceding 12 months. Self-reported pain in different regions across both grades and sex are detailed in Table 2 .

Among those who complained of musculoskeletal pain, over a quarte of them $(114,27.8 \%)$ had missed school due to the pain in the preceding 12 months. The majority of them attributed it to pain in one region $(79,69.3 \%)$. The three most commonly reported areas were: lower back $(37,32.5 \%)$, shoulders $(30,26.3 \%)$ and upper back $(28,24.6 \%)$. Of those who reported having missed school, half (59, $51.8 \%$ ) had sought medical help (visited a doctor, drungtsho (traditional physician), or traditional/local healer). 
After adjusting for age, sex, time spent on activities after school, and usage of safety features, children who carried schoolbags weighing $>10 \%$ of body weight (adjusted $\mathrm{OR}=2.75 ; 95 \% \mathrm{Cl} 1.27,5.60 ; p<0.001$ ) and those carrying heavy bags over just one shoulder (adjusted $\mathrm{OR}=$ $5.72,95 \% \mathrm{Cl}=1.07,30.41 ; p=0.041$ ) were more likely to report musculoskeletal pain.

Table 2. Self-reported pain in different body regions as mapped in the Standardized Nordic Body Map Questionnaire among students of Thimphu, Bhutan in 2017.

\begin{tabular}{cccccccccc}
\hline & \multicolumn{4}{c}{ Grade 8} & \multicolumn{4}{c}{ Grade 10} & \multicolumn{2}{c}{ Overall } \\
Male & Female & \multicolumn{2}{c}{ Male } & Female & & \\
$\mathrm{n}$ & $(\%)$ & $\mathrm{n}$ & $(\%)$ & $\mathrm{n}$ & $(\%)$ & $\mathrm{n}$ & $(\%)$ & $\mathrm{n}$ & $(\%)$ \\
\hline
\end{tabular}

\section{Body Region}

\begin{tabular}{|c|c|c|c|c|c|c|}
\hline & $34(36.6)$ & 46 & 47.4) & 54 & \\
\hline \multicolumn{2}{|c|}{ Upper back } & $37(39.8)$ & 40 & $(41.2)$ & $46(39.7)$ & $60(44.4) 18$ \\
\hline \multicolumn{2}{|c|}{ Lower back } & $33(35.5)$ & 43 & $(44.3)$ & $55(47.4)$ & 69 \\
\hline \multicolumn{2}{|c|}{ Hips/Thighs } & $28(30.1)$ & 20 & $(20.6)$ & $30(25.9)$ & 52 \\
\hline \multicolumn{2}{|l|}{ Knees } & 31 & 34 & (35.1) & $39(33.6)$ & 50 \\
\hline \multicolumn{2}{|l|}{ Ankles } & $33(35.5)$ & 17 & $(17.5)$ & $30(25.9)$ & 39 \\
\hline \multirow{3}{*}{ Shoulder } & Rigr & 11( & 12 & $(12.4)$ & $18(15.5)$ & $10(7.4)$ \\
\hline & Left & $3(3.2)$ & 4 & $(4.1)$ & 9 (7.8) & $14(10.4)=$ \\
\hline & Both & $43(46.2)$ & 46 & $(47.4)$ & $38(32.8)$ & $60(4$ \\
\hline \multirow{3}{*}{ Elbow } & Right & $5 \quad(5.4)$ & 5 & $(5.2)$ & $5 \quad(4.3)$ & $7(5.2)$ \\
\hline & Left & $4 \quad(4.3)$ & 2 & $(2.1)$ & $1 \quad(0.9)$ & $3(2.2) \quad 57 \quad(12.9$ \\
\hline & Both & $2(2.2)$ & 8 & $(8.2)$ & $6 \quad(5.2)$ & $9(6.7)$ \\
\hline \multirow{3}{*}{$\begin{array}{l}\text { Vrists/ } \\
\text { tands }\end{array}$} & Right & $13(14.0)$ & 11 & $(11.3)$ & $14(12.0)$ & $15(11.1)$ \\
\hline & Lef & $6 \quad(6.5)$ & 1 & (1.0) & & $8 \quad(5.9) \quad 107$ \\
\hline & Both & $6 \quad(6.5)$ & 14 & $(14.4)$ & $6 \quad(5.2)$ & 13 (9.6) \\
\hline
\end{tabular}

\section{Discussion}

Nearly half of the students in grade 8 and less than a quarter of students in grade 10 carried school bags heavier than recommended. These proportions are lower than that reported for students in Ireland and Kuwait (70\% each), but similar to that reported for Uganda ( $31 \%$ ). $6,8,12$ The mean weight of schoolbags was heavier among grade 8 students than grade 10 students despite the fact that older students were prescribed more textbooks ( 20 textbooks for 9 academic subjects in grade 10 compared with 15 textbooks for 6 subjects in grade 8). Older students might be carrying only the notebooks that are required for the day or borrow textbooks from other students.

The prevalence of musculoskeletal pain in our sample was considerably higher (93.2\%) than those reported: $88.2 \%$ in Uganda $69.3 \%$ Spain; $60 \%$ in India. ${ }^{12,14,15,19-21}$ All these studies document selfreported pain but only few have quantified the severity of the pain reported using tools such as visual analogue scale. ${ }^{8,22}$ Comparison between these studies must be interpreted with the scope of definitions used for each study. We used the Standardized Nordic body map for anatomical localization of musculoskeletal pain. $13,18,20$ Though its body map picture is useful especially when administered among children, its use in our setting has not been validated and could have led to over-reporting of musculoskeletal pain.
There was a significant difference between how heavy students perceived their bags to be and the actual weight of the bags. In addition to the factors that determine the perception of load heaviness, ${ }^{23}$ socio-cultural context plays an important role in our setting. Many of the parents of the current school children grew up in an era where there were no roads and report of having carried loads that were heavier than the current schoolbags and in traditional ways without safety measures of contemporary comparisons. Load perception may also be linked to recognition and reporting of musculoskeletal pain.

The negative impact of physiological and anatomical changes in the thoraco-lumbar spine resulting from chronic load bearing may be reduced by using bags with safety features. Most of the school bags that we studied did not have safety features; even if these features were present, many students did not use them. This calls for interventions to encourage students to adopt healthy backpack habits. Vidal et al reported an intervention programme of a combination of theory and practical feedback sessions that may be easily adopted in the classrooms in our setting. ${ }^{19}$

In our sample, carrying school bags weighing $>10 \%$ bodyweight and carrying the bag over one shoulder compared to carrying it strapped over two shoulders were significant risk factors in reporting musculoskeletal pain. Reports of such pain at such an early age are of concern given that Bhutan has over 214,000 students in total, which makes up $30 \%$ of the country's population. ${ }^{16,24}$ Adolescents who report musculoskeletal pain are at an increased risk of mental disorders especially anxiety and mood disorders, subsequent increased mental healthcare use and an increased odds of being absent from work in the long term. ${ }^{25,26}$ In the short term, students have stayed absent from school due to musculoskeletal pain. The proportion of students who missed school due to musculoskeletal pain are higher than that reported in other studies.12 In our study, age and sex were not risk factors for musculoskeletal pain. $11,22,27$

\section{Recommendations}

Heavy schoolbags can be addressed by making sure that parents and their children are aware of the risks, encouraging use of methods to reduce risk (use of safety features, carrying the bag over both shoulders) and effective ergonomic education. ${ }^{20}$ Providing secure storage facilities 19 in schools is a viable option for Bhutan where education is provided free of cost. Awareness needs to be created among parents and teachers on the selection and use of schoolbags that have safety features.

\section{Limitations}

In our study, the weight of schoolbags was measured only on the day of data collection. The cumulative effect of heavy schoolbags over the academic year and pain prevalence in the short- and long term were not assessed. ${ }^{8}$ Musculoskeletal pain was self-reported and we had not collected clinical details about the pain. Therefore, we were unable to test for other effects that could have influenced the reporting of pain and also the goodness-of-fit of the logistic regression model. The study was conducted in one large urban and suburban area, Thimphu. The distance from school, type of school bags and mode of transport are different in rural areas and therefore a similar study is recommended. For the multistage clustered sampling technique used in this study, we were unable to perform weighted analysis due to lack of adequate factors collected during the study.

\section{Conclusions}

The prevalence of musculoskeletal pain was high. Nearly a third of the students carried schoolbags that were heavier than that recommended. The weight of a schoolbag relative to the body weight was a significant risk factor for experiencing musculoskeletal pain. 


\section{References}

1. Steele E, Bialocerkowski A, Grimmer K. The postural effects of load carriage on young people -- a systematic review. BMC Musculoskelet Disord. 2003 Jun 17;4(1):12.

2. Brackley HM, Stevenson JM, Selinger JC. Effect of backpack load placement on posture and spinal curvature in prepubescent children. Work. 2009 May 28;32(3):351-360.

3. Korovessis P, Koureas C, Zacharatos S, Papazisis Z. Backpacks, back pain, sagittal spinal curves and trunk alignment in adolescents: a logistic and multinomial logistic analysis. Spine (Phila Pa 1976). 2005 Jan 15;30(2):247-55.

4. Negrini S, Negrini A. Postural effects of symmetrical and asymmetrical loads on the spines of schoolchildren. Scoliosis. 2007 Jul 9;2(1):8.

5. Walicka-Cupryś K, Skalska-Izdebska R, Rachwał M, Truszczyńska A. Influence of the Weight of a School Backpack on Spinal Curvature in the Sagittal Plane of Seven-Year-Old Children. Biomed Res Int. 2015 Aug 18;2015.

6. Dockrell S, Blake C, Simms C. Guidelines for schoolbag carriage: An appraisal of safe load limits for schoolbag weight and duration of carriage. Work. 2015 Jun 11;53(3):679-688.

7. Perrone M, Orr R, Hing W, Milne N, Pope R. The Impact of Backpack Loads on School Children: A Critical Narrative Review. Int I Environ Res Public Health. 2018 Nov 12;15(11).

8. Akbar F, AlBesharah M, Al-Baghli J, et al. Prevalence of low Back pain among adolescents in relation to the weight of school bags. BMC Musculoskelet Disord. 2019 Jan 22;20(1):37.

9. Ministry of Health. Annual Health Bulletin, 2017. Thimphu: Ministry of Health, Royal Covernment of Bhutan; 2017.

10. Hwang J, Louie PK, Phillips FM, An HS, Samartzis D. Low back pain in children: a rising concern. Eur Spine J. 2019 Feb;28(2):211-213.

11. Noll M, Candotti CT, da Rosa BN, Loss JF. Back pain prevalence and associated factors in children and adolescents: an epidemiological population study. Rev Saude Publica. 2016;50:31.

12. Mwaka ES, Munabi IG, Buwembo W, Kukkiriza J, Ochieng J. Musculoskeletal pain and school bag use: a cross-sectional study among Ugandan pupils. BMC Res Notes. 2014 Apr 9;7(1):222.

13. Whittfield J, Legg SJ, Hedderley DI. Schoolbag weight and musculoskeletal symptoms in New Zealand secondary schools. Appl Ergon. 2005 Mar;36(2):193-198.

14. Al-Saleem SA, Ali A, Ali SI, Alshamrani AA, Almulhem AM, Al-Hashem MH. A Study of School Bag Weight and Back Pain among Primary School Children in Al-Ahsa, Saudi Arabia. Epidemiol (Sunnyvale, Calif). 2016 Jan 30;6(1).
15. Yoon J-C. Correlations between Muscle Activities and Strap Length and Types of School Bag during Walking. J Phys Ther Sci. 2014 Dec 25;26(12):1937-1939.

16. Annual Education Statistics 2017. Thimphu: Ministry of Education, Royal Covernment of Bhutan; 2017.

17. Tshering G. Carrying heavy school bags adversely impacts students. The Kuensel. 2017.

18. Kuorinka I, Jonsson B, Kilbom A, et al. Standardised Nordic questionnaires for the analysis of musculoskeletal symptoms. Appl Ergon. 1987 Sep;18(3):233-237.

19. Vidal J, Borràs PA, Ponseti FJ, Cantallops J, Ortega FB, Palou P. Effects of a postural education program on school backpack habits related to low back pain in children. Eur Spine J. 2013 Apr;22(4):782-787.

20. Syazwan Al, Azhar MNM, Anita AR, et al. Poor sitting posture and a heavy schoolbag as contributors to musculoskeletal pain in children: an ergonomic school education intervention program. J Pain Res. 2011 Sep 14;4:287-296.

21. Briggs AM, Smith AJ, Straker LM, Bragge P. Thoracic spine pain in the general population: Prevalence, incidence and associated factors in children, adolescents and adults. A systematic review. BMC Musculoskelet Disord. 2009 Jun 29;10:77.

22. Wirth B, Knecht C, Humphreys K. Spine day 2012: spinal pain in Swiss school children-- epidemiology and risk factors. BMC Pediatr. 2013 Oct 5;13(1):159.

23. Nicolet T, Mannion AF, Heini P, Cedraschi C, Balagué F. No kidding: low back pain and type of container influence adolescents' perception of load heaviness. Eur Spine J. 2014 Apr;23(4):794-799.

24. National Statistics Bureau. Population and Housing Census of Bhutan 2017 . National Report. Thimphu: National Statistics Bureau, Bhutan; 2018.

25. Eckhoff C, Straume B, Kvernmo S. Multisite musculoskeletal pain in adolescence and later mental health disorders: a population-based registry study of Norwegian youth: the NAAHS cohort study. BMJ Open. 2017 Feb 10;7(2):e012035.

26. Mose $S$, Christiansen DH, Jensen JC, Andersen JH. Widespread pain - do pain intensity and care-seeking influence sickness absence? - A population-based cohort study. BMC Musculoskelet Disord. 2016 May 4;17:197.

27. Kędra A, Czaprowski D. Epidemiology of Back Pain in Children and Youth Aged 10-19 from the Area of the Southeast of Poland. Biomed Res Int. 2013 Jul $31 ; 506823$.

\section{Acknowledgments}

We thank the Ministry of Education, Royal Government of Bhutan and the school principals for their support; and the students who participated in this study.

\section{Conflict of Interest Statement Ct Funding}

The Authors have no funding, financial relationships or conflicts of interest to disclose.

\section{Author Contributions}

Conceptualization: T.D., S. T. T., S. Y., and K. W. Methodology: T.D., S. T. T., S. Y., and K. W. Validation: T.D., S. T. T., S. Y., and K. W. Formal Analysis: T.D., S. T. T., S. Y., and K. W. Data Curation: T.D., S. T. T., S. Y., and K. W. Resources: T.D., S. T. T., S. Y., and K. W. Writing - Original Draft: T.D., S. T. T., S. Y., and K. W. Writing - Review at Editing: T.D., S. T. T., S. Y., and K. W. Supervision: T.D., and K. W. Project Administration: T.D., S. T. T., S. Y., and K. W. Cite as:

Dorji T, Tamang ST, Yoezer S, Wangdi K. The Weight of Schoolbags and Musculoskeletal Pain in Children of Selected Schools in Thimphu, Bhutan: A Crosssectional Study. Int J Med Students. 2019 May-Aug;7(2):29-32. 